Original Article

Lucia Dantas Giglio $0^{1,2}$ Cláudia Maria de Felício $0^{1,2}$ Luciana Vitaliano Voi Trawitzki ${ }^{1,2}$ (C)

\title{
Orofacial functions and forces in male and female healthy young and adults
}

\section{Keywords}

Bite force

Stomatognathic system

Strength assessment

Tongue

Cheeks

Lips

\section{Palavras-chave}

Força de mordida Sistema estomatognático

Avaliação de força

Língua

Bochechas

Lábios

\section{Correspondence address:}

Luciana Vitaliano Voi Trawitzki.

Departamento de Oftalmologia, Otorrinolaringologia e Cirurgia de Cabeça e Pescoço, Faculdade de Medicina de Ribeirão Preto, Universidade de São Paulo, Ribeirão Preto, São Paulo, Brasil. Av. dos Bandeirantes, 3900, Ribeirão Preto, SP,

Brasil. CEP: 14049-900.

E-mail: luvoi@fmrp.usp.br

Received: February 22, 2019.

Accepted: November 12, 2019

\begin{abstract}
Purpose: To determine reference values of orofacial myofunctional condition and orofacial forces in healthy young and adults. Methods: Fifty young and adults were selected from a total of 316 voluntaries. Participants were assessed with the Orofacial Myofunctional Evaluation with Scores (OMES) for the investigation of orofacial myofunctional condition. The maximum forces of bite, cheeks, tongue (anterior and posterior regions), and lips were assessed with an electronic dynamometer (values expressed in Newtons). Force values were obtained by average of three repeated measurement. The technical error of measurements was calculated for all variables. Results: There were no differences in orofacial myofunctional condition between men and women. Men presented higher values of orofacial forces compared to women. Conclusion: The normal values of orofacial myofunctional condition and orofacial forces were determined in healthy and adults Brazilian men and women. The values obtained in this study from healthy Brazilian may help in the diagnosis of alterations in orofacial motor function and contribute for their therapeutic management.
\end{abstract}

\section{RESUMO}

Objetivo: determinar valores de referência da condição miofuncional orofacial e forças orofaciais em adultos jovens saudáveis. Método: foram selecionados 50 jovens e adultos de um total de 316 voluntários. Os participantes foram avaliados pelo protocolo de Avaliação Miofuncional Orofacial com Escores (AMIOFE) para a investigação da condição miofuncional orofacial. As forças de mordida, bochechas, língua (regiões anterior e posterior) e lábios foram avaliadas por um dinamômetro eletrônico e os valores foram registrados em Newtons. Os valores de força foram obtidos pela média de três medidas repetidas. O erro técnico do método foi calculado para todas as variáveis. Resultado: Não houve diferenças na condição miofuncional orofacial entre homens e mulheres. Homens apresentaram maiores valores de forças orofaciais em relação às mulheres. Conclusões: Os valores normais da condição miofuncional orofacial e das forças orofaciais foram determinados em homens e mulheres brasileiros saudáveis e adultos. Os valores obtidos neste estudo de brasileiros saudáveis podem auxiliar no diagnóstico de alterações na função motora orofacial e contribuir para o seu manejo terapêutico.

The study was conducted at the Craniofacial Research Support Center, University of São Paulo - USP Ribeirão Preto (SP), Brazil.

${ }^{1}$ Departamento de Oftalmologia, Otorrinolaringologia e Cirurgia de Cabeça e Pescoço, Faculdade de Medicina de Ribeirão Preto, Universidade de São Paulo, Ribeirão Preto, São Paulo, Brasil.

${ }^{2}$ Núcleo de Pesquisa em Morfofisiologia do Complexo Craniofacial (NAP-CF), Universidade de São Paulo, Ribeirão Preto, São Paulo, Brasil.

Conflict of interests: nothing to declare.

Financial support: this study was supported by Fundação de Amparo à Pesquisa do Estado de São Paulo (FAPESP, process no. 2011/09793-8) and by Fundação de apoio ao Ensino e a Pesquisa do Hospital das Clínicas da Faculdade de Medicina de Ribeirão Preto da Universidade de São Paulo (FAEPA-HCFMRP-USP). distribution, and reproduction in any medium, without restrictions, as long as the original work is correctly cited. 


\section{INTRODUCTION}

Face and tongue muscles are crucial for the performance of orofacial functions including mastication, speech, deglutition, and facial expressiveness ${ }^{(1)}$, which are relevant for one's health and quality of life. When the performance of orofacial muscles is impaired, problems may occur in mastication and in the manipulation and propulsion of the food bolus during deglutition, for example.

Some diseases as dentofacial deformities ${ }^{(2)}$, temporomandibular disorder ${ }^{(3,4)}$, obstructive sleep apnea ${ }^{(5)}$ have associated orofacial functions impairment.

The use of validated protocols in the investigation of these and other diseases may help to the understanding of each orofacial impairment. Moreover tasks that demand maximal performance, such as those used in the assessment of maximal muscle force, may reveal possible neuromuscular impairments. They can also serve as a diagnostic tool and provide information for therapeutic planning ${ }^{(1)}$.

Strength can be defined as the ability to produce large forces in short bursts. High levels of force are produced when additional motor units are recruited ${ }^{(6)}$.

Different orofacial forces have been investigated in a number of studies, including bite force ${ }^{(2,7-11)}$, tongue force ${ }^{(1,11-16)}$, cheek force ${ }^{(7,13,14)}$, and lip force $\mathrm{f}^{(1,13,17)}$.

There are several instruments available to measure these forces and it is crucial to have reference values established for each instrument. Therefore, a commercially available in the Brazil electronic dynamometer which allows to measure the different orofacial forces was chosen for the current study. This device has been used for investigation of muscle force $e^{(2,8-10,12)}$.

The reference values obtained from a healthy sample sorted by sex are useful for clinical and research proposals to investigate whether deviations exist in patients and what their magnitude, thus helping to determine which patients need to undergo treatment for the rehabilitation of orofacial conditions and forces, as well as to analyze outcome measures at post-treatment.

This study aimed to establish reference values of orofacial myofunctional condition and maximal forces for healthy young and adult Brazilian men and women.

\section{METHODS}

A total of 316 subjects from the community were invited to take part in the study and 311 attended. All voluntaries were informed about the study aims and procedures. Then they were interviewed and a screening of the general healthy, oral healthy, occlusion, muscles and orofacial functions was performed. Two hundred and forty five did not meet inclusion criteria and six subjects declined to participate in the study. Sixty voluntaries were evaluated for the orofacial conditions and forces. After all evaluation, 10 subjects were excluded and only 50 subjects fulfilled all the criteria for inclusion in the study. Details of the sample composition can be seen in Figure 1.

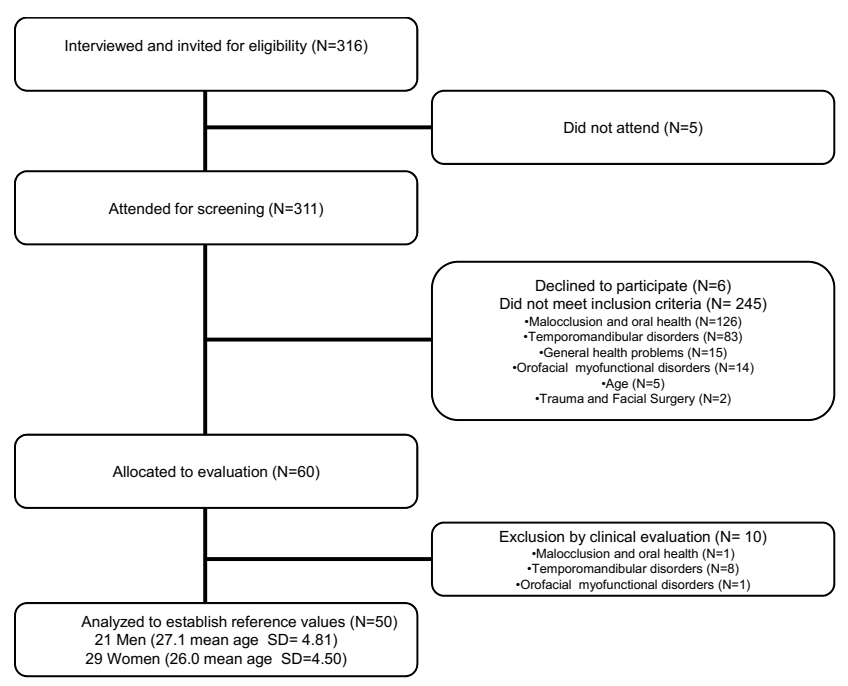

Figure 1. Flowchart of sample composition

Written informed consent was obtained from each participant. The study protocol was examined and approved by the Research Ethics Committee under process number 8669/2009.

The inclusion criteria were: age ranging from 18 to 40 years, good general and oral health, normocclusion, absence of orofacial myofunctional disorder.

The exclusion criteria were: temporomandibular joint disorders (TMD), history of facial trauma; head or neck surgery and tumors; respiratory, neurological, and psychiatric problems, cognitive disorders; orthodontic and/or speech therapy over the previous year; continued medication use (pain killers, antiinflammatories, or psychotropic medications), tooth absence (except the third molars); dental caries and pain; periodontal disease; malocclusion and dentofacial deformities. Subjects who reported or presented any of these items were excluded from the sample.

Previously obtained descriptive statistics were used to estimate the minimum number of participants required for a statistical analysis with $80 \%$ statistical power (type II error, beta) and with alpha (type I error) set at 5\%. The estimated numbers according to the variable were: OMES total score ( $\mathrm{n}=$ $16)$; tongue forces $(n=20)$; cheeks force $(n=15)$, bite force $(n=14)$ and lips force $(n=10)$.

The sample composition is illustrated on flowchart (Figure 1).

The orofacial myofunctional evaluation was performed by one examiner (L.D.G.) using the Orofacial Myofunctional Evaluation with Scores Protocol (OMES), a validated and reliable instrument ${ }^{(3)}$.

In this protocol, the examiner assigns pre-established scores for the appearance/posture of lips, jaw, cheeks, face, tongue, and hard palate; mobility of lips, tongue, jaw, and cheeks; and orofacial functions of respiration, deglutition, and mastication. Higher scores indicate better performance, that is, better orofacial myofunctional condition. The examiner can use the total score and also the sum of scores in each category for their analyses. The two methods of analysis were used in this study. 
The participants responded and were examined according to the Research Diagnostic Criteria for TMD (RDC/TMD) ${ }^{(18)}$. This protocol investigate de presence of sign and symptoms of TMD, limitation and deviation of mandible motion, presence of pain and noises on temporomandibular joint. When presence of any sign or symptom were detected, the participant was excluded.

Orofacial forces were measured by the same examiner (L.D.G.) with an electronic dynamometer (Kratos ${ }^{\circledR}$ model DDK/M, Cotia, SP, Brazil). The device has two metal strips separated by a $10-\mathrm{mm}$ gap and fitted with $13-\mathrm{mm}$ diameter and 2 -mm thick Teflon disks on the tips. The precise control of the measures obtained is made through a "point zero" key and a peak recording device facilitates the readings of maximum bite force during measures. According to the Brazilian Association of Technical Standards (which provides the calibration of force of metallic material for general use), the precision is $\pm 1 \%$ of the read point, from the initial $10 \%$ of the scale. This dynamometer was developed for the assessment of bite force and was adapted in this study for the assessment of the other orofacial forces ${ }^{(2,7,12)}$.

The device's metal strips were covered with disposable latex finger cots during the tests. Three measures of each maximum isometric orofacial force were recorded from volunteers by one examiner, with a 1-minute interval between each trial, and the average of the three values was used in the analyses. The measures were acquired alternately and values were recorded in Newtons (N). Force values were obtained by average of three repeated measurement.

For bite force, the device was placed in the region of the first molar teeth and volunteers were instructed to bite as strong as possible, with the right and left sides of the arcade alternately, respecting the resting intervals ${ }^{(12)}$ (Figure 2). It was calculated the mean values of the right and left side measures.

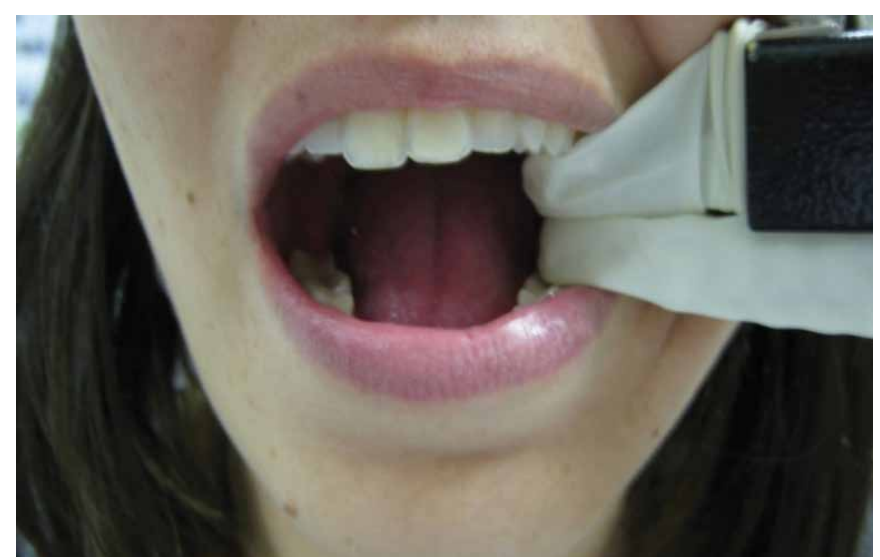

Figure 2. Illustration showing the procedure to measure maximum isometric bite force on the left side

To asses cheek force, the dynamometer was placed in the region of the oral vestibule between the molar teeth and the jugal mucosa (Figure 3). Participants were instructed to compress the device as strongly as possible with their cheeks, on the left and right sides consecutively, respecting the rest intervals ${ }^{(7)}$. The mean values of measures collected on each side were used in the analyses.

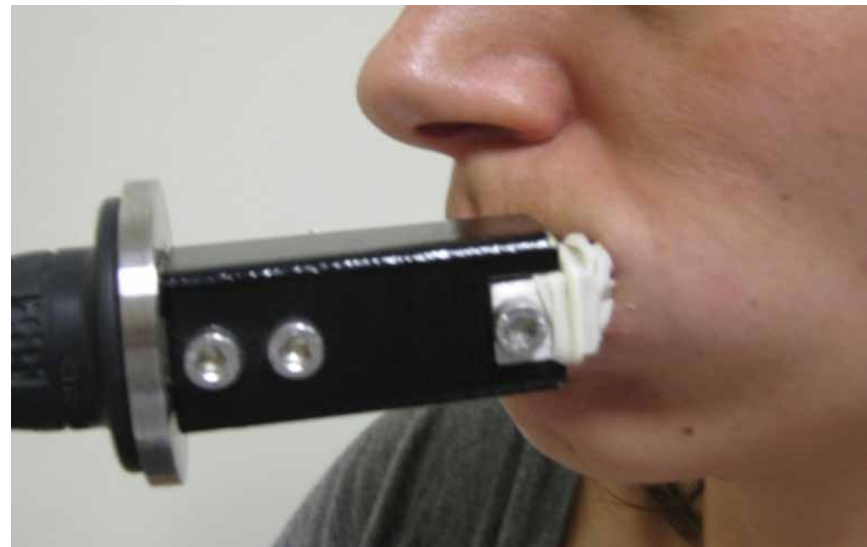

Figure 3. Illustration showing the procedure to measure maximum isometric cheek force on the left side

Tongue force was measured in two regions: the anterior portion of the tongue (anterior tongue force), with the device placed behind the superior incisive teeth ${ }^{(2)}$ and in the upper surface of the tongue, with the device placed in the region of the hard palate ${ }^{(7)}$ (dorsum tongue force). In both trials, volunteers were asked to raise their tongue against the Teflon disk on the metal strip with the highest possible force while keeping their jaw stable in order to avoid the contact of teeth with the measuring device (Figure 4).

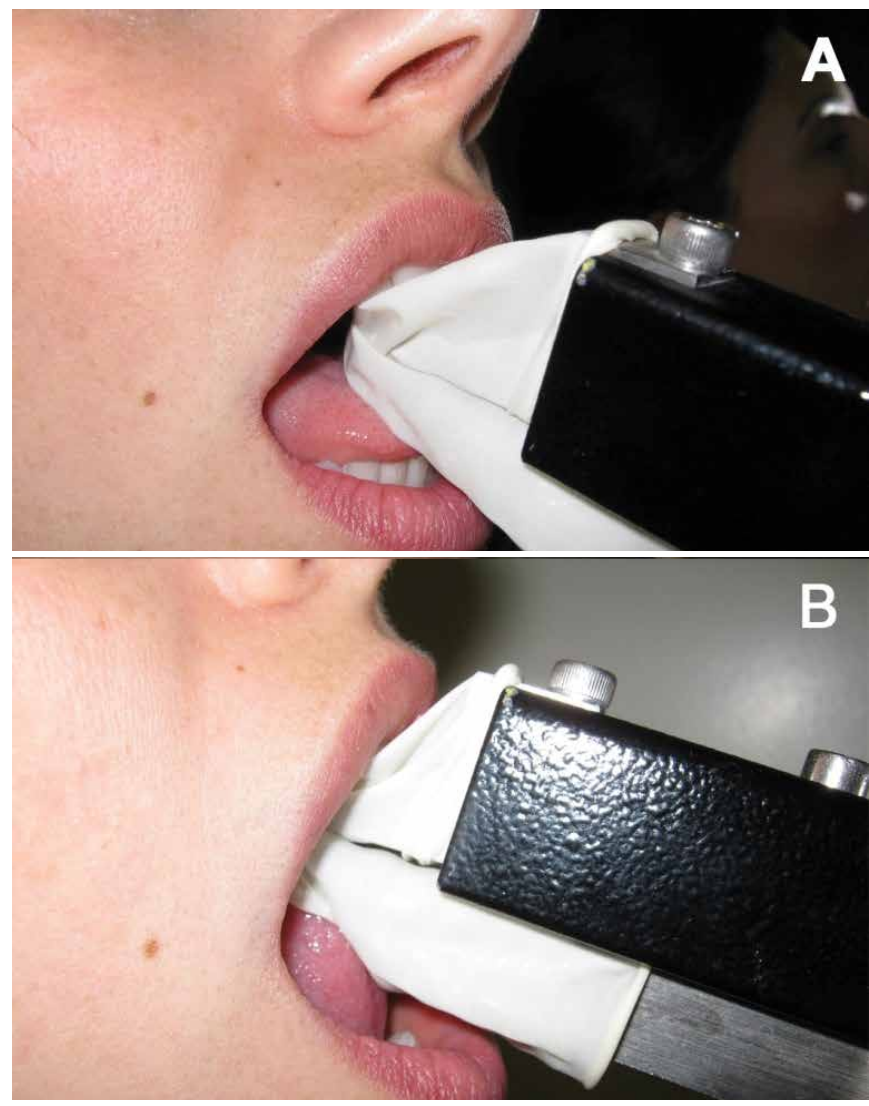

Figure 4. Illustration of the procedures used to measure the maximum isometric tongue force in two regions: $(A)$ anterior and (B) dorsum

For the assessment of lip force, volunteers were instructed to keep their teeth in contact in order to maintain their jaws 
stable. The dynamometer was placed perpendicular to the midline of the central superior incisive teeth, making their vestibular surfaces touch. The participants were then asked to compress the Teflon disks by simultaneously rounding their lips in the sense of contraction of the orbicularis oris muscle as strongly as possible (Figure 5). Therefore, the lip force in this study corresponds to the force applied by both lips indistinctively.

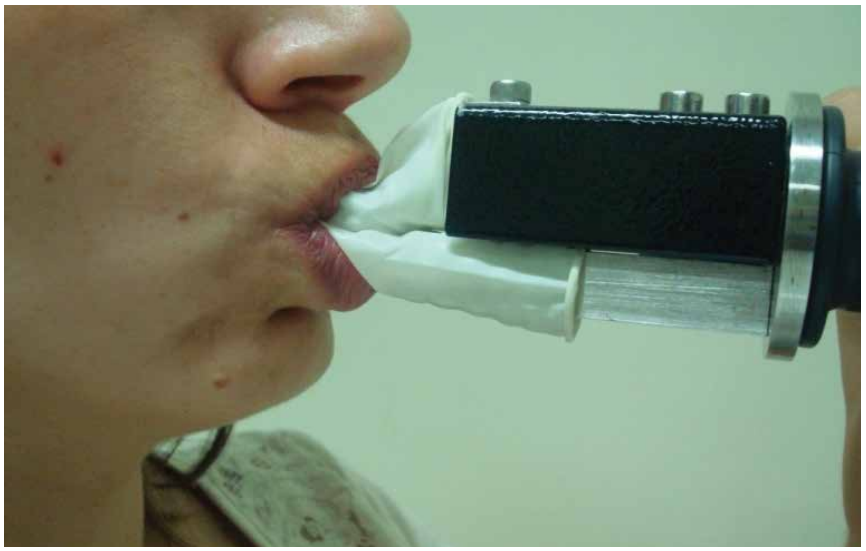

Figure 5. Illustration of the procedure to measure maximum isometric lip force

\section{Data analysis}

The Technical Error of Measurements (TEM) was estimated for all variables of study by Dahlberg's formula $\left[\sum\left(D^{2}\right) / 2 \mathrm{x}\right.$ $\mathrm{n}]^{0-5}$, where D stands for the difference between two repeated measures (with intervals ranging between one week and four months) and $\mathrm{n}$ refers to the sample size. Data from eight participants collected by the same examiner were used.

The reliability of the orofacial forces was analyzed by the interclass correlation coefficient (ICC), based on measurements performed on twelve voluntaries, by two independent raters (ICC Inter- raters), and two repeated measurements by the same rater (ICC Intra-rater).

Descriptive statistics of the variables were calculated separately for men and women. Measures of bite and cheek force on the left and right sides were compared using the Student t-test (paired samples) and no differences were found between them $(p>0.05)$. Therefore, the mean values from the left and right sides were used in the analysis of these variables. For comparison of men and women were used the Mann-Whitney test (orofacial myofunctional condition) and the unpaired Student t-test (orofacial forces). A continuity correction was applied in order to avoid type I error (alpha error). Age and body max index were analyzed separately by unpaired Student t-test.

All analyses were made with the software Statistic 13 (Dell Software, Inc., Aliso Viejo, CA, United States), with the level of significance set at 0.05 .

\section{RESULTS}

All methods showed good repeatability. The values of the TEM were low and smaller than the values of standard deviations of the sample. The test-retest intra-rater reliability ranged from good to excellent, while the inter-rater ranged from moderate to excellent (Table 1).

Table 1. Technical Error of Measurements (TEM), Intraclass correlation coefficient (ICC)

\begin{tabular}{cccc}
\hline Variable & TEM & $\begin{array}{c}\mathrm{ICC}^{*} \\
\text { Intra-rater }\end{array}$ & $\begin{array}{c}\mathrm{ICC}^{*} \\
\text { Inter-rater }\end{array}$ \\
\cline { 2 - 4 } OMC & 1.32 & 0.92 & 0.81 \\
Bite Force (N) & 70.00 & 0.99 & 0.96 \\
$\begin{array}{c}\text { Cheek Force } \\
(\mathrm{N})\end{array}$ & 2.62 & 0.94 & 0.69 \\
$\begin{array}{c}\text { Togue Force } \\
\text { a (N) }\end{array}$ & 2.76 & 0.87 & 0.84 \\
$\begin{array}{c}\text { Togue Force } \\
\text { d (N) }\end{array}$ & 3.19 & 0.96 & 0.77 \\
Lip Force (N) & 0.90 & 0.85 & 0.74 \\
\hline
\end{tabular}

*Absolute agreement

Caption: $\mathrm{OMC}=$ Orofacial Myofunctional Condition; Tongue Force $\mathrm{a}=$ anterior region; Tongue Force $\mathrm{d}=$ dorsum region; $\mathrm{N}=$ Newtons.

Male and female participants had no significant differences in age $($ median $=27 \times 26)$ or BMI $($ median $=24 \times 23)$ (Table 2). Likewise, there were no significant differences in the OMES protocol scores between men and women ( $p$ $>0.05)$. The results of orofacial myofunctional evaluation are presented in Table 3.

Regarding orofacial forces, men had significantly higher orofacial strength than women $(\mathrm{p} \leq 0.01)$, as shown in Table 4 .

Table 2. Age, weight, height and body mass index (BMI) of male and female participants

\begin{tabular}{|c|c|c|c|c|c|c|c|c|c|}
\hline & \multirow[b]{2}{*}{ Mean } & \multicolumn{2}{|c|}{$\begin{array}{l}\text { Male } \\
n=21\end{array}$} & \multicolumn{6}{|c|}{$\begin{array}{l}\text { Female } \\
\qquad n=29\end{array}$} \\
\hline & & SD & Median & $\mathrm{Cl}-95 \%$ & Mean & SD & Median & Cl-95\% & p-value* \\
\hline Age & 27.10 & 4.81 & 27.00 & $24.91-29.28$ & 26.00 & 4.50 & 26.00 & $24.29-27.71$ & 0.413324 \\
\hline Weight & 76.29 & 10.96 & 76.00 & $71.30-81.27$ & 62.36 & 11.94 & 60.00 & $57.81-66.90$ & 0.0001 \\
\hline Height & 1.77 & 0.05 & 1.76 & $1.75-1.79$ & 1.64 & 0.05 & 1.63 & $1.62-1.66$ & $<0.0001$ \\
\hline BMI & 24.34 & 3.29 & 23.55 & $22.85-25.84$ & 23.16 & 3.75 & 22.66 & $21.74-24.59$ & 0.254078 \\
\hline
\end{tabular}

*Unpaired Student t-test

Caption: $\mathrm{n}=$ sample size; $\mathrm{SD}=$ standard deviation; $\mathrm{Cl}=$ confidence interval. 
Table 3. Normal reference values for Orofacial Myofunctional Condition collected with the OMES protocol of male and female participants

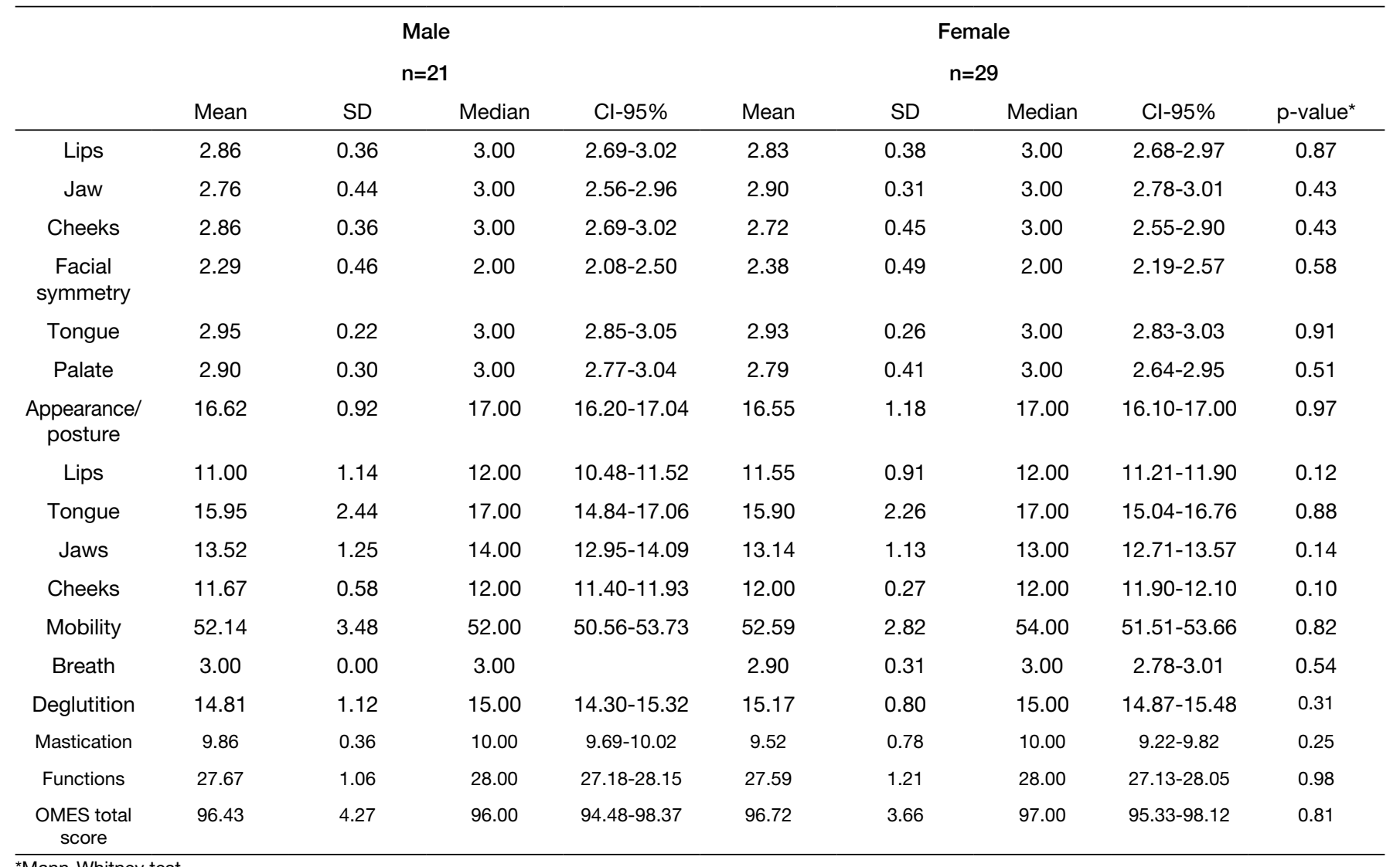

*Mann-Whitney test

Caption: $\mathrm{n}=$ sample size; $\mathrm{SD}=$ standard deviation; $\mathrm{Cl}=$ confidence interval

Table 4. Normal reference values for orofacial forces of male and female participants

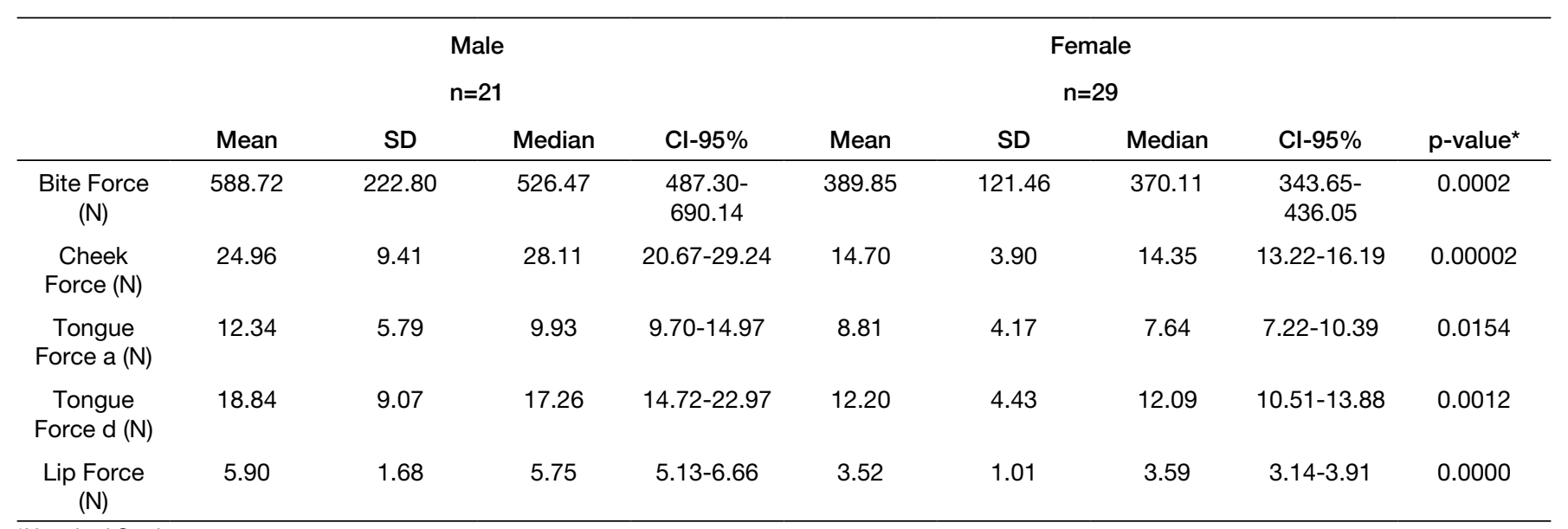

*Unpaired Student t-test

Caption: $\mathrm{n}=$ sample size; $\mathrm{SD}=$ standard deviation; $\mathrm{Cl}=$ confidence interval $\mathrm{N}=$ Newton; Tongue Force a= anterior region; Tongue Force $\mathrm{d}=\mathrm{dors}$ (m) region. 


\section{DISCUSSION}

Orofacial muscles and functions can be assessed using different methods. However, these methods must be adequate for the assessment of each variable, besides being reproducible. Once these requirements are fulfilled, it is important to have established normality values and limits, and this was the purpose of our study.

Since sexual dimorphism can affect biomechanical variables $^{(13-15,19,20)}$, all the analyses were conducted separately by sex. Our population was composed of young and adults ranged from 18-40 years to avoid that aging factors influencing the results and performance of the orofacial musculature, such as dental losses, decreased muscle mass ${ }^{(11)}$. Other authors have investigated orofacial forces in young adults population and they have established similar age range in their studies ${ }^{(7,17,19)}$.

Subjects were selected from rigorous inclusion criteria to evaluate the stomatognathic system, as it was considered that any change, even if slight, could interfere in the results and not reflect the performance of a reference sample. Of the 316 invited subjects, most were excluded due to occlusal problems $(31.3 \%)$ and sign and symptoms of TMD (26.3\%). In Brazil, the prevalence of malocclusion in the 15-19 age group is $20.3 \%$, according to data from the Health Ministry, in 2010. In other studies, prevalence of malocclusion among Brazilian adults ranged from 45.6 to $63.5 \%{ }^{(21,22)}$. The prevalence of TMD in Brazil is $9.2 \%$ considering three or more symptoms but it increase to $39.2 \%$ when at least one symptom is considered ${ }^{(23)}$. Considering some degree of TMD pain, the prevalence is $36.2 \%{ }^{(24)}$. Therefore, the reasons why most of subjects were excluded in the present study are relatively frequent in the Brazilian population. However, these factors may have negative influence on the orofacial musculature and the sample should be composed of individuals without any alteration.

It is important to highlight that, in order to compare the results of different studies, methodological differences must be taken into account including, for example, the instruments used and characteristics of the sample.

The results of the OMES protocol showed that the partial and total scores did not differ significantly between men and women in the typical adults subjects, indicating that male and female participants can be considered as a single group for research purposes. However, it is not yet clear whether the same holds true for conditions that affect orofacial function and have different prevalence between males and females. Some parameters of chewing in the OMES protocol presented differences between adolescent boys and girls ${ }^{(20)}$. Park and Shin ${ }^{(25)}$ found that time, size of food and cycle length may also differ in men and women, but these authors point out that these differences are still unclear, requiring further investigation.

When compared with the OMES validation study ${ }^{(3)}$, the scores of orofacial myofunctional evaluation found in our investigation were similar to the mean values found in the control group and higher than those of patients with TMD.

The orofacial forces assessed were higher in men compared to women, as previously reported for the bite ${ }^{(8)}$, $\operatorname{cheek}^{(7,13,14)}$, dorsum tongue ${ }^{(12)}$, and lip strength ${ }^{(17)}$. This sex difference was not observed for the force measured in the anterior region of the tongue, a task similar to the anterior tongue elevation using the Iowa Oral Performance Instrument (IOPI) (without difference between men and women $)^{(13,15)}$. A possible explanation is that the human tongue has special characteristics related to the fine control during speech; particularly its anterior region which takes part in the production of the more complex sounds such as fricatives and liquids. Due to a specialized speech motor control center in the cerebral cortex and the innervation ${ }^{(26)}$, the tongue is able to change position and shape three-dimensionally in a rapid manner and yet temporal and spatially coordinated with other articulators. Moreover, the adult human tongue is composed of $54 \%$ of slow muscle fibers, which are resistant to fatigue and generally involved in activities requiring precise control of low forces ${ }^{(27)}$.

The mean bite force values for female and male participants in the current study were higher than the values previously found for Brazilian control groups in investigations that used the same model of electronic dynamometer ${ }^{(8,10,12)}$, and similar to the results of another study that analyzed data from healthy men and women as a single group ${ }^{(9)}$. The error of the method of the electronic dynamometer was tested before with bite force and no differences were observed between two different evaluation sessions ${ }^{(8,28)}$.

As occurred in regard to bite force, the values of tongue force in the present investigation were higher in males and females and in both regions analyzed compared to a previous study with Brazilian healthy subjects ${ }^{(2)}$. This may be the result of differences in sample selection, as the control group in that investigation was not selected according to a specific protocol to assess orofacial myofunctional evaluation.

Conversely, bite force values in our sample were lower than the values described by Lujan-Climent et al. ${ }^{(7)}$ in a Spanish group. The study by the latter authors was the only one that assessed cheek force using a similar device to ours, and the values described in their article were higher in both men and women compared to our participants, the same being true in respect to tongue forces.

Several factors may be involved in the discrepancy between these results, including the diet and genetic diversity of the populations, but also the sample characteristics in the study by Lujan-Climent et al. ${ }^{(7)}$ : among 100 subjects assessed by those authors, 41 had TMD, and a part of this group also had posterior crossbite. Individuals with crossbite present alterations in Wilson's curve and require increased contraction of the buccinators in the performance of their role during mastication $^{(29)}$ that may have interfered mainly with cheek force or even with the placement of the dynamometer.

Regarding maximum lip force, the present assessment using the dynamometer is an original approach. In healthy adults, the instruments most commonly used to assess this function have different shapes and measure forces in other directions, which makes the comparison of results difficult. With the IOPI and the oral probe, the direction of the force exerted is similar; however, the units of measurement are different, thus the dynamometer measures force while the other instruments measure pressure. 
The Multidirectional Lip Closing Force System (MLCFS) has a similar shape to the dynamometer and measures forces in similar directions; although the height of the former is approximately $10 \mathrm{~mm}$ greater than that of the dynamometer. Despite the differences between the instruments, the lip force values obtained with the MLCFS were quite similar to the results presented here for both men and women ${ }^{(17)}$.

Studies that used the IOPI, which was developed to measure tongue force and adapted to measure other orofacial forces including cheek force ${ }^{(13,30)}$ and lip force ${ }^{(13)}$, with their results showing great variation. Clark \& Solomon ${ }^{(13)}$ attributed this variation to methodological aspects (instructions given to participants) and to the aid provided by adjacent structures such as teeth, for example.

Further, the results available about the tongue strength show variations between different populations. According to Vanderwegen et al. ${ }^{(31)}$, the values found for tongue pressure in European subjects were lower than those described for the American population and closer to the values found in Asian subjects.

Therefore, the standardization of procedures and the establishment of normality parameters are crucial for research in this field.

Tasks that demand maximum force or pressure are used in research $^{(1,2,7-10,13-16)}$; because this is the best way to standardize tests across different subjects and, thus, to reduce variability so that reliable information concerning the functioning of orofacial structures can be obtained. In addition, one way to summarize the maximum force is through the average of 3 measurements ${ }^{(16)}$, as used in this study. It should be noted, however, that the forces exerted during normal functions such as mastication, deglutition ${ }^{(19)}$ and speech $^{(27)}$ are lower.

It is important to understand which aspects of a given orofacial function are impaired when muscle strength is affected and consider that there is a close relationship between quality of life and oral function ${ }^{(14)}$.

The results of this study can be useful to determine which patients need a intervention based on oral motor exercises target to improve orofacial forces, as well as in the follow-up of therapeutic management, besides serving as a parameter for the definition of adequate control groups for research.

Despite there are others specific instruments to measure tongue, lip and cheek forces, the electronic dynamometer can be useful because it is national, portable, practical, fast, simple to use, noninvasive and has low cost. Previous studies have shown results for bite force ${ }^{(8,10,12)}$, tongue force ${ }^{(2)}$ and cheek force $^{(7)}$. Besides, the use of a single equipment to explore the orofacial forces can facilitate the diagnostic research.

\section{CONCLUSION}

The results showed that, in healthy young and adult Brazilian, there is no difference in the orofacial myofunctional condition between sex, however men present greater orofacial force values than women, except for the anterior tongue force. The reference values for orofacial myofunctional evaluation and different orofacial forces in healthy men and women were established and can be useful in the diagnosis of orofacial movement dysfunctions and contribute to their therapeutic management.

\section{REFERENCES}

1. Arakawa I, Koide K, Takahashi M, Mizuhashi F. Effect of the tongue rotation exercise training on the oral functions in normal adults - Part 1 investigation of tongue pressure and labial closure strength. J Oral Rehabil. 2015;42(6):407-13. PMid: 25640889. DOI: 10.1111/joor.12271.

2. Silva JB, Giglio LD, Regalo SH, de Mello-Filho FV, Trawitzki LV. Effect of dentofacial deformity on maximum isometric tongue strength. J Oral Rehabil. 2013;40(4):247-51. PMid: 23216277. DOI: 10.1111/joor.12020.

3. Felício CM, Medeiros AP, Melchior MO. Validity of the 'protocol of orofacial myofunctional evaluation with scores' for young and adult subjects. J Oral Rehabil. 2012;39(10):744-53. PMid: 22852833. DOI: 10.1111/j.1365-2842.2012.02336.x.

4. Melchior MO, Machado BC, Magri LV, Mazzetto MO. Effect of speechlanguage therapy after low-level laser therapy in patients with TMD: a descriptive study. CoDAS. 2016;28(6):818-22. DOI: $10.1590 / 2317-$ $1782 / 20162015099$

5. Valarelli LP, Corradi AMB, Grechi TH, Eckeli AL, Aragon DC, Küpper DS, Almeida LA, Sander HH, de Felício CM, Trawitzki LVV, Valera FCP. Cephalometric, muscular and swallowing changes in patients with OSAS. J Oral Rehabil. 2018;45(9):692-701. PMid: 29889982. DOI: 10.1111/ joor. 12666.

6. Clark HM. Neuromuscular treatments for speech and swallowing: A tutorial Am J Speech - Lang Pathol. 2003;12(4):400-15. PMid: 14658992. DOI: 10.1044/1058-0360(2003/086).

7. Lujan-Climent M, Martinez-Gomis J, Palau S, Ayuso-Montero R, Salsench $\mathrm{J}$, Peraire M. Influence of static and dynamic occlusal characteristics and muscle force on masticatory performance in dentate adults. Eur J Oral Sci. 2008;116(3):229-36. PMid: 18471241. DOI: 10.1111/j.16000722.2008.00530.x.

8. Palinkas M, Nassar MS, Cecílio FA, Siéssere S, Semprini M, Sousa JPM, et al. Age and gender influence on maximal bite force and masticatory muscles thickness. Arch Oral Biol. 2010;55(10):797-802. PMid: 20667521. DOI: 10.1016/j.archoralbio.2010.06.016.

9. Pepato AO, Palinkas M, Regalo SC, de Medeiros EH, de Vasconcelos PB, Sverzut CE, et al. Effect of surgical treatment of mandibular fracture: electromyographic analysis, bite force, and mandibular mobility. J Craniofac Surg. 2014;25(5):1714-20. PMid: 25203573. DOI: 10.1097/ SCS.0000000000000968.

10. Takaki P, Vieira M, Bommarito S. Maximum bite force analysis in different age groups. Int Arch of Otorhinolaryngol. 2014;18(3):272-6. DOI: $10.1055 / \mathrm{s}-0034-1374647$.

11. Hara K, Tohara H, Kenichiro K, Yamaguchi K, Ariya C, Yoshimi K, Nakane A, Minakuchi S. Association between tongue muscle strength and masticatory muscle strength. J Oral Rehabil. 2018. PMid: 30353915. DOI: 10.1111/joor.12737. [Epub ahead of print].

12. Trawitzki LV, Silva JB, Regalo SC, Mello-Filho FV. Effect of class II and class III dentofacial deformities under orthodontic treatment on maximal isometric bite force. Arch Oral Biol. 2011;56(10):972-6. PMid: 21440242. DOI: 10.1016/j.archoralbio.2011.02.018.

13. Clark H M, Solomon NP. Age and sex differences in orofacial strength. Dysphagia. 2012;27(1):2-9. PMid: 21350818. DOI: 10.1007/s00455011-9328-2.

14. Takahashi M, Koide K, Arakawa I, Mizuhashi F. Association between perioral muscle pressure and masticatory performance. J Oral Rehabil. 2013;40(12):909-15. PMid: 24118057. DOI: 10.1111/joor.12105.

15. Prandini EL, Totta T, Bueno MRS, Rosa RR, Giglio LD, Trawitzki LVV, et al. Analysis of tongue pressure in Brazilian young adults. CoDAS. 2015;27(5):478-82. https://dx.DOI.org/10.1590/2317-1782/20152014225.

16. Araújo TG, Rodrigues TM, Furlam RMMM, Las Casas EB, Motta AR. Avaliação da reprodutibilidade de um instrumento para medição da força 
axial da língua. CoDAS. 2018;30(3):e20170191 DOI: 10.1590/23171782/20182017191.

17. Murakami M, Adachi T, Nakatsuka K, Kato T, Oishi M, Masuda Y. Gender differences in maximum voluntary lip closing force during lip pursing in healthy young adults. J Oral Rehabil. 2012;39(6):399-404. PMid: 22115393. DOI: $10.1111 / \mathrm{j} .1365-2842.2011 .02268 . x$.

18. Dworkin SF, LeResche L. Research diagnostic criteria for temporomandibular disorders: review, criteria, examinations and specifications, critique. J Craniomandib Disord. 1992;6(4):301-55. PMid: 20213033. PMCID: PMC3157036.

19. Youmans SR, Youmans GL, Stierwalt JA. Differences in tongue strength across age and gender: is there a diminished strength reserve? Dysphagia. 2009;24(1):57-65. PMid: 18690406. DOI: 10.1007/s00455-008-9171-2.

20. Scudine GO, Pedroni-Pereira A, Araujo DS,. Prado DGA, Rossi AC, Castelo PM. Assessment of the differences in masticatory behavior between male and female adolescents. Physiol Behav. 2016;163:115-22. PMid: 27143251. DOI: 10.1016/j.physbeh.2016.04.053.

21. Claudino D, Traebert J. Malocclusion, dental aesthetic self-perception and quality of life in a 18 to 21 year-old population: a cross section study. BMC Oral Health. 2013;13:3. PMid: 23295063. PMCID: PMC3556057. DOI: $10.1186 / 1472-6831-13-3$.

22. dos Santos A, Florentino VGB, Sarmento DJS, Cavalcanti AL, Prevalence of malocclusion and orthodontic treatment needs in adult patients. Acta Scientiarum: Health Sci. 2011;33(2):197-202. PMid: 32166082. PMCID: PMC7041309. DOI: 10.4025/actascihealthsci.v33i2.9507.

23. Gonçalves DA, Dal Fabbro AL, Campos JA, Bigal ME, Speciali JG. Symptoms of temporomandibular disorders in the population: an epidemiological study. J Orofac Pain. 2010;24(3):270-8. PMid: 20664828.

24. Progiante PS, Pattussi MP, Lawrence HP, Goya S, Grossi PK, Grossi ML. Prevalence of temporomandibular disorders in an adult brazilian community population using the research diagnostic criteria (axes I and II) for temporomandibular disorders (The Maringá Study), Int J Prosthodont. 2015;28(6):600-9. PMid: 26523719. DOI: 10.11607/ijp.4026.
25. Park S, Shin WS. Differences in eating behaviors and masticatory performances by gender and obesity status. Physiol Behav. 2015;138:69-74 PMid: 25447481. DOI: 10.1016/j.physbeh.2014.10.001.

26. Mu L, Sanders I. Human tongue neuroanatomy: Nerve supply and motor endplates. Clin Anat. 2010;23(7):777-91. PMid: 20607833. PMCID PMC2955167. DOI: 10.1002/ca.21011.

27. Sanders I, Mu L, Amirali A, Su H, Sobotka S. The human tongue slows down to speak: muscle fibers of the human tongue. Anat Rec (Hoboken). 2013;296(10):1615-27. PMid: 23929762. PMCID: PMC3787083. DOI: 10.1002/ar.22755

28. da Silva RJ, Issa JP, Semprini M, da Silva CH,. de Vasconcelos PB, Celino $\mathrm{CA}$, et al. Clinical feasibility of mandibular implant overdenture retainers submitted to immediate load. Gerodontology. 2011;28(3):227-32. PMid: 20609008. DOI: 10.1111/j.1741-2358.2010.00374.x.

29. Dawson PE. Evaluation, diagnosis, and treatment of occlusal problems. ed 2. St Louis: Mosby; 1989. p.347-59. Portuguese version.

30. Clark HM, O'Brien K, Calleja A, Corrie SN. Effects of directional exercise on lingual strength. J Speech Lang Hear Res. 2009;52(4):1034-47. PMid: 19641080. DOI: 10.1044/1092-4388(2009/08-0062).

31. Vanderwegen J, Guns C, Van Nuffelen G, Elen R, De Bodt M. The influence of age, sex, bulb position, visual feedback, and the order of testing on maximum anterior and posterior tongue strength and endurance in healthy belgian adults. Dysphagia. 2013;28(2):159-66. DOI: 10.1007/s00455-0129425-x. PMid: 22983359. DOI: 10.1007/s00455-012-9425-x.

\section{Authors' contribution}

LDG: collection of data and writing of the manuscript, CMF: analysis of data, writing and revision of the manuscript, LVVT: study design, analysis of data, writing and revision of the manuscript. 